\title{
The Influence of Heat Treatment on the Static and Dynamic Sorptive Behavior of Moso Bamboo (Phyllostachys pubescens)
}

\author{
Yuxiang Huang $\mathbb{D}^{\mathrm{D}}$, Ru Liu, Fandan Meng, Yanglun Yu $\mathbb{D}^{D}$, and Wenji Yu \\ Key Laboratory of Wood Science and Technology of State Forestry Administration, Research Institute of Wood Industry, \\ Chinese Academy of Forestry, Xiangshan Road, Haidian District, Beijing 100091, China \\ Correspondence should be addressed to Yanglun Yu; yuyanglun@caf.ac.cn
}

Received 4 January 2019; Revised 2 April 2019; Accepted 4 April 2019; Published 2 May 2019

Guest Editor: Changlei Xia

Copyright (C) 2019 Yuxiang Huang et al. This is an open access article distributed under the Creative Commons Attribution License, which permits unrestricted use, distribution, and reproduction in any medium, provided the original work is properly cited.

\begin{abstract}
The influence of heat treatment on moisture sorption behavior of moso bamboo (Phyllostachys pubescens), especially under dynamic sorption conditions, was investigated. Moso bamboo was heated to 180 and $200^{\circ} \mathrm{C}$ for $8 \mathrm{~h}$ to investigate the chemical components and sorptive behavior at sinusoidal relative humidity $(\mathrm{RH})$ and constant humidity. The results of chemical components revealed that the content of holocellulose, $\alpha$-cellulose, and hemicellulose decreased while that of lignin increased slightly with increasing treatment temperatures. The results of static adsorption at constant $\mathrm{RH}$ showed that $200^{\circ} \mathrm{C}$ treated bamboo exhibited the lowest moisture content and moisture sorption coefficient. The results of dynamic sorptive behavior indicated that the moisture content changed sinusoidally but lagged behind the triggering sinusoidal RH changes. Heat-treated bamboo presented greater phase lag and smaller amplitudes of moisture content and sorption hysteresis due to the hemicellulose removal.
\end{abstract}

\section{Introduction}

Bamboo, regarded as an attractive natural material in terms of strength and cost [1] due to its rapid growth, affordability, workability, and high mechanical resistance [2], is widely used in light building materials, fencing, scaffolding, and musical instruments [3]. In recent years, bamboo is developed to produce bamboo-based composites to improve its added value, such as bamboo plywood [4], laminated bamboo lumber [5, 6], bamboo particleboard [7], and bamboo fiber-reinforced polymer composite [8].

However, as is common with other bio-based materials, bamboo is susceptible to dimensional instability by being exposed to moisture or water due to its natural hygroscopicity, which greatly limited its application [9]. Heat treatment has been shown to be an effective way to improve the dimensional stability of wood and wood products and a great deal of research has been done on the heat treatment of wood [1014]. These studies have showed that the cell wall components underwent thermal degradation during the heat treatment, which reduced the number of hydrophilic hydroxyl groups, thus increasing wood hydrophobicity. Recently, thermal modification technology has also been used to improve the bamboo properties by using heat treatment of wood as reference. Some relevant research has been carried out in the past in terms of heat treatment process [15], color change and dimensional stability [16], mechanical property change $[1,9,16]$, and durability of heat treatment [17]. Their results showed that the heat treatment is a green and environmentally friendly modification method. With the help of heat conducting medium, the physical and chemical properties of bamboo can be modified by heat alone. The change of these properties was closely related to the process parameters such as temperature, time, and medium of heat treatment. The increase of heat treatment temperature and time led to the decrease of elastic modulus and flexural strength of bamboo $[9,16]$. The bending strength of bamboo treated with $200^{\circ} \mathrm{C}$ decreased by $31-60 \%$ [3]. Wahab et al. found that the equilibrium moisture content of heat-treated bamboo was significantly lower than that of untreated bamboo and the lower moisture absorption led to better dimensional stability of bamboo [17]. The results by Azadeh and Ghavami also indicated that increasing the temperature and time exposure of heat treatment reduced the hygroscopic property of bamboo [2]. In terms of the hygroscopic properties of heat-treated bamboo, these studies 
were carried out under static conditions with constant relative humidity $(\mathrm{RH})$. However, in fact, when bamboo is utilized and processed, the $\mathrm{RH}$ is changing, which can be regarded as an approximate sinusoidal change [18]. Herein, the effects of heat treatment on the dynamic sorptive behavior at sinusoidal $\mathrm{RH}$ as well as its static sorptive behavior at constant $\mathrm{RH}$ were investigated, which is expected to contribute to a better control of moisture and dimensional stability of bamboo products in service.

\section{Materials and Methods}

2.1. Materials Preparation. Moso bamboo (Phyllostachys pubescens L.), aged 4 years, was harvested from the forest in Anji, Zhejiang. Its diameters ranged from $7-10 \mathrm{~cm}$ and culmwall thickness was from 7 to $10 \mathrm{~mm}$. The bamboo culm was sawn into small bamboo slivers with dimensions of $50 \mathrm{~mm}$ (length) $\times 20 \mathrm{~mm}$ (width) $\times 5 \mathrm{~mm}$ (thickness) after removing the inner and outer bamboo skin. The bamboo sliver was dried at $85^{\circ} \mathrm{C}$ for $24 \mathrm{~h}$ to an approximate moisture content of $10 \%$ in an oven. Then, the samples were kept in a conditioned room at $20^{\circ} \mathrm{C}$ and $50 \%$ relative humidity for 2 weeks.

2.2. Heat Treatment. The slivers were oven-dried at $103^{\circ} \mathrm{C}$ and weighed before the thermal treatment. The dried samples were placed in an iron bucket in an oven and heated at 180 and $200^{\circ} \mathrm{C}$, respectively, for $8 \mathrm{~h}$. Inspired by the chestnut roasted in sand with brown sugar, the bamboo samples were covered by sand as protecting medium, which can make the bamboo samples uniformly heated and avoid burning. The sand was passed through a $40 \mathrm{~mm}$ sieve, and any glass or stone pieces were manually removed to obtain a homogeneous mix prior to testing. Afterwards, the samples were taken out and washed with water and oven-dried again.

2.3. Chemical Components. The bamboo slivers before and after heat treatment were ground and passed through 40-60 mesh sieves prior to chemical analyses.

2.3.1. Holocellulose. The content of holocellulose was determined by GB/T 2677.10-1995. Firstly, benzene-ethanol $\left(\mathrm{C}_{8} \mathrm{H}_{10} \mathrm{O}\right)$ was used to extract the bamboo powders of $2 \mathrm{~g}$ (accurate to $0.0001 \mathrm{~g}$ ). Then, the powder was infused with $65 \mathrm{~mL}$ distilled water and placed in $75^{\circ} \mathrm{C}$ water bath. The powders were treated with $0.5 \mathrm{~mL}$ acetic acid $\left(\mathrm{CH}_{3} \mathrm{COOH}\right)$ and 0.6 g sodium chlorite $\left(\mathrm{NaClO}_{2}\right)$ per hour till they became white. After filtering and washing to neutrality, the mixture was washed three times with acetone and dried in an oven at $105 \pm 2^{\circ} \mathrm{C}$ to reach a constant weight. The content of holocellulose was determined by

$$
\text { The content of holocellulose }(\%)=\frac{m_{1}}{m_{0}} \times 100
$$

where $m_{0}(\mathrm{~g})$ is the oven-dry weight of the sample and $m_{1}(\mathrm{~g})$ is the oven-dry weight of the extracted holocellulose.

The aforementioned procedure was repeated; the arithmetic average value of the two measurements was taken as the result. The error between two measurements should not exceed $0.4 \%$.
2.3.2. $\alpha$-Cellulose Analysis. The content of $\alpha$-cellulose was determined by GB/T 744-1989. $2 \mathrm{~g}$ (accurate to $0.0001 \mathrm{~g}$ ) of oven-dried holocellulose obtained from Section 2.3.1 was mixed with $30 \mathrm{~mL} \mathrm{NaOH}$ with a mass fraction of $17.5 \%$. After placing in $25^{\circ} \mathrm{C}$ water bath for $45 \mathrm{~min}$, the mixture was added with $30 \mathrm{~mL}$ distilled water and then it was filtered three times with $25 \mathrm{~mL} \mathrm{NaOH}$ with a mass fraction of $9.5 \%$ and then washed again with $400 \mathrm{~mL}$ distilled water. Next, the residue was added with $\mathrm{CH}_{3} \mathrm{COOH}$ and the system was kept for $5 \mathrm{~min}$. Complete a vacuum filtration process to remove the acetic acid and wash the residue until the filtrate solution was no longer acidic. Finally, the residue was dried in an oven at $105 \pm 2^{\circ} \mathrm{C}$ to reach a constant weight. The content of $\alpha$ cellulose was calculated by

$$
\text { The content of } \alpha \text {-cellulose }(\%)=\frac{m_{1}}{m_{0} / W_{1}} \times 100
$$

where $m_{0}(\mathrm{~g})$ is the oven-dry weight of the extracted holocellulose, $m_{1}(\mathrm{~g})$ is the oven-dry weight of the extracted $\alpha$ cellulose, and $W_{1}(\%)$ is the content of holocellulose.

The aforementioned procedure was repeated; the arithmetic average value of the two measurements was taken as the result. The error between two measurements should not exceed $0.4 \%$.

2.3.3. Hemicelluloses. The content of hemicellulose of bamboo samples was estimated by the equation proposed by Zhao et al. [19].

$$
\begin{aligned}
& \text { the content of hemicellulose (\%) } \\
& =\text { the content of holocellulose (\%) } \\
& \text { - the content of } \alpha \text {-cellulose (\%) }
\end{aligned}
$$

2.3.4. Acid-Insoluble Lignin. The content of acid-insoluble lignin (lignin for short) was determined by GB/T 2677.8-1994. Firstly, $\mathrm{C}_{8} \mathrm{H}_{10} \mathrm{O}$ was used to extract the bamboo powders of $1 \mathrm{~g}$ (accurate to $0.0001 \mathrm{~g}$ ). After hydrolyzing with $15 \mathrm{~mL}$ sulphuric acid $\left(\mathrm{H}_{2} \mathrm{SO}_{4}\right)$ with a mass fraction of $72 \%$, the bamboo powders were place in a $20^{\circ} \mathrm{C}$ water bath for $2.5 \mathrm{~h}$. Then, the mixture was added with distilled water until the total volume reached $560 \mathrm{~mL}$ and boiled at $100^{\circ} \mathrm{C}$. During the period, the distilled water was continuously added to maintain the total volume of $560 \mathrm{~mL}$, and then it was kept static to deposit lignin. The content of lignin was determined by

$$
\text { The content of } \operatorname{lignin}(\%)=\frac{m_{2}}{m_{0}} \times 100
$$

where $m_{0}(\mathrm{~g})$ is the oven-dry weight of the bamboo powder and $m_{2}(\mathrm{~g})$ is the oven-dry weight of the collected lignin.

The aforementioned procedure was repeated; the arithmetic average value of the two measurements was taken as the result. The error between two measurements should not exceed $0.2 \%$.

2.3.5. Hot Water Extractives. The content of hot water extractives (extractives for short) was determined by GB/T 2677.41993. About $2 \mathrm{~g}( \pm 0.1 \mathrm{mg})$ of bamboo powders was added into 
TABLE 1: Chemical component contents of bamboo during heat treatment.

\begin{tabular}{lccccc}
\hline Labels & Holocelluloses $(\%)$ & $\alpha$-cellulose $(\%)$ & Hemicellulose $(\%)$ & Lignin $(\%)$ & Extractives $(\%)$ \\
\hline Untreated & $68.21(0.65)$ & $38.25(2.38)$ & $29.96(1.23)$ & $22.06(0.88)$ & $6.34(2.41)$ \\
$180^{\circ} \mathrm{C}$ treated & $60.72(0.06)$ & $36.73(0.07)$ & $23.99(0.56)$ & $25.67(3.12)$ & $7.95(1.32)$ \\
$200^{\circ} \mathrm{C}$ treated & $55.86(2.47)$ & $35.14(1.70)$ & $20.72(3.43)$ & $31.67(3.08)$ & $8.82(0.35)$ \\
\hline
\end{tabular}

Note. values in the brackets are deviations.

$200 \mathrm{~mL}$ distilled water with temperature of $95-100^{\circ} \mathrm{C}$. After placing in $100^{\circ} \mathrm{C}$ water bath for $3 \mathrm{~h}$, the mixture was put into a reflux condensation tube. Prior to washing with distilled water, the solution was filtered with a tared sintered glass crucible. Then the residues were dried at in an oven to reach constant weight. The content of extractives was calculated by the following:

The content of hot water extractives (\%)

$$
=\frac{m_{0}-m_{3}}{m_{0}} \times 100
$$

where $m_{0}(\mathrm{~g})$ is the oven-dry weight of the bamboo power and $m_{3}(\mathrm{~g})$ is the oven-dry weight of the sample after hot water extracting.

The aforementioned procedure was repeated; the arithmetic average value of the two measurements was taken as the result. The error between two measurements should not exceed $0.2 \%$.

2.4. Static Adsorption at Constant RH. The heat-treated bamboo powder and untreated bamboo powder obtained from 2.3 were placed into boxes and then the boxes were transferred into 3 kinds of desiccators containing the saturated salt solutions $\left(\mathrm{NaCl}, \mathrm{K}_{2} \mathrm{CO}_{3}\right.$ and $\left.\mathrm{LiCl}\right)$ at a conditioned room with constant temperature of $25^{\circ} \mathrm{C}$. The $\mathrm{RH}$ of the three salt solutions is $75 \%, 45 \%$, and $11 \%$, respectively. Every 24 hours, the samples were taken out of the desiccators and weighed until their weight reaches a constant weight. The number of repeated specimens under each condition is 6 . The moisture content at constant RH was the average value of 6 specimens.

2.5. Hailwood-Horrobin Sorption Theory. The sorption behavior of heat-treated bamboo and untreated bamboo was explored using the $\mathrm{H}-\mathrm{H}$ sorption theory [20]. In the theory, the sorption isotherm of wood can be described as a parabola by

$$
\begin{aligned}
\frac{h}{m} & =A+B h-C h^{2} \\
A & =\frac{W}{18} \frac{1}{K_{2}\left(K_{1}+1\right)}, \\
B & =\frac{W}{18} \frac{K_{1}-1}{K_{1}+1}, \\
C & =\frac{W}{18} \frac{K_{1} K_{2}}{K_{1}+1}
\end{aligned}
$$

where $h$ is the relative humidity, $m$ is the moisture content of bamboo, $K_{1}$ is the equilibrium constant, where the hydrated bamboo is formed from the dissolved water and dry bamboo, $K_{2}$ is the equilibrium constant between dissolved water and water vapor, $W$ is the molar mass of wood, and $18 / W$ is the moisture content corresponding to complete hydration of all the available sorption sites.

Hydrated water $\left(m_{h}\right)$ and dissolved water $\left(m_{s}\right)$ can be further figured out through

$$
\begin{aligned}
& m_{h}=\frac{(18 / W) K_{1} K_{2} h}{\left(1+K_{1} K_{2} h\right)} \\
& m_{s}=\frac{(18 / W) K_{2} h}{\left(1-K_{2} h\right)}
\end{aligned}
$$

2.6. Dynamic Sorption at Sinusoidal RH. The heat-treated samples and untreated samples were conditioned at $20^{\circ} \mathrm{C}$ in $45 \% \mathrm{RH}$ and submitted to a cyclic $\mathrm{RH}$ oscillation, where the RH was changed sinusoidally between $75 \%$ and $45 \%$ RH at a constant temperature of $20^{\circ} \mathrm{C}$. Prior to dynamic sorption, all the samples were placed over saturated salt solutions of $\mathrm{K}_{2} \mathrm{CO}_{3}$ (the corresponding $\mathrm{RH}$ was $45 \%$ ) over 10 days for preconditioning. The dynamic sorption testing was carried out in a conditioning oven (DHS 225, YaShiLin Co., Ltd., Beijing) [21]. The RH changed for 4 cycles and each cyclic period lasted $6 \mathrm{~h}$. In line with the predetermined schedule, the $\mathrm{RH}$ in the conditioning oven was programmed to change at discrete steps. The $\mathrm{RH}$ (sensitivity $\pm 1 \%$ ) was monitored by a thermorecorder (TR-72Ui, T and d Co., Ltd, Japan) which was placed closed to the specimens. During the experimental process, the weight changes were measured at every 5 min intervals by an electronic analytical balance (ME104E, Mettlertoledo Co., Ltd., Columbus, OH, USA) (sensitivity $\pm 0.1 \mathrm{mg}$ ). During the whole dynamic testing process, the measurement data can be automatically recorded by the personal computer without opening the door of the oven.

\section{Results and Discussion}

3.1. Chemical Composition. The results of the chemical composition analysis indicated that the content of holocellulose and hemicellulose declined after heat treatment and kept on decreasing as rising the temperature (Table 1). The relative content of $\alpha$-cellulose decreased slightly while that of lignin and extractives increased, which was consistent with the results reported by Lee et al. [15].

3.2. Static Adsorption at Constant RH. Figure 1 shows the equilibrium moisture contents (EMC) of the samples at various humidities. The EMCs of heat-treated samples were lower than those of untreated samples under any humidity 
TABLE 2: Values for parameters in Hailwood-Horrobin sorption theory and moisture sorption coefficient $Z$.

\begin{tabular}{lccc}
\hline Parameters & Untreated & $180^{\circ} \mathrm{C}$ treated & $200^{\circ} \mathrm{C}$ treated \\
\hline$K_{1}$ & 10.29 & 6.74 & 6.5 \\
$K_{2}$ & 0.88 & 0.91 & 0.92 \\
$18 / W(\%)$ & 4.27 & 3.19 & 3.11 \\
$Z$ & 0.19 & 0.17 & 0.15 \\
\hline
\end{tabular}
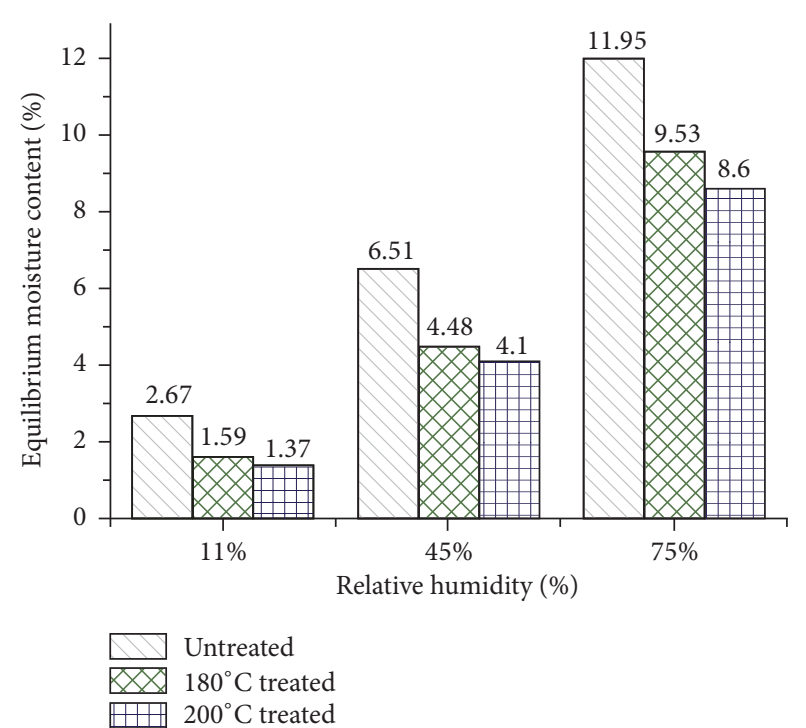

FIgURE 1: Equilibrium moisture contents (EMC) of the samples at various humidities.

condition, and the higher the temperature of heat treatment temperature, the lower the EMC of bamboo. This was because the chemical changes during heat treatment resulted in the decrease of the amount of sites which are able to absorb bound water [12]. Using this data, the main parameters given in (6) and (7) can be calculated and the corresponding values are summarized in Table 2 .

As seen from Table $2, K_{2}$ values of all the samples were approximately 0.9 , similar to the values for solid wood [22]. All the values of $18 / W$ of bamboo flours fell in the range of $3 \%$ to $4 \%$. In other words, the MC of samples should be between $3 \%$ and $4 \%$ when all the hydroxyls available are saturated by a monolayer of adsorbed water. A comparison of $18 / \mathrm{W}$ values between samples indicated that the $18 / W$ values for heat-treated samples were lower than the untreated samples, demonstrating a reduction of free hydroxyl groups after heat treatment due to the partial removal of hemicellulose. The hemicellulose loss of the heat-treated sample at $200^{\circ} \mathrm{C}$ was higher than that at $180^{\circ} \mathrm{C}$ (Table 1), and accordingly the former showed a minimum $18 / W$ value.

The sorption isotherms calculated using EMC of bamboo samples according to $\mathrm{H}-\mathrm{H}$ sorption theory are shown in Figure 2. The fitting curve agrees well with the experimental data, confirming the effectiveness of the data in Table. Moreover, the final water absorption readings of the samples were in the following order: untreated sample $>$ heat-treated sample at $180^{\circ} \mathrm{C}>$ heat-treated sample at $200^{\circ} \mathrm{C}$.

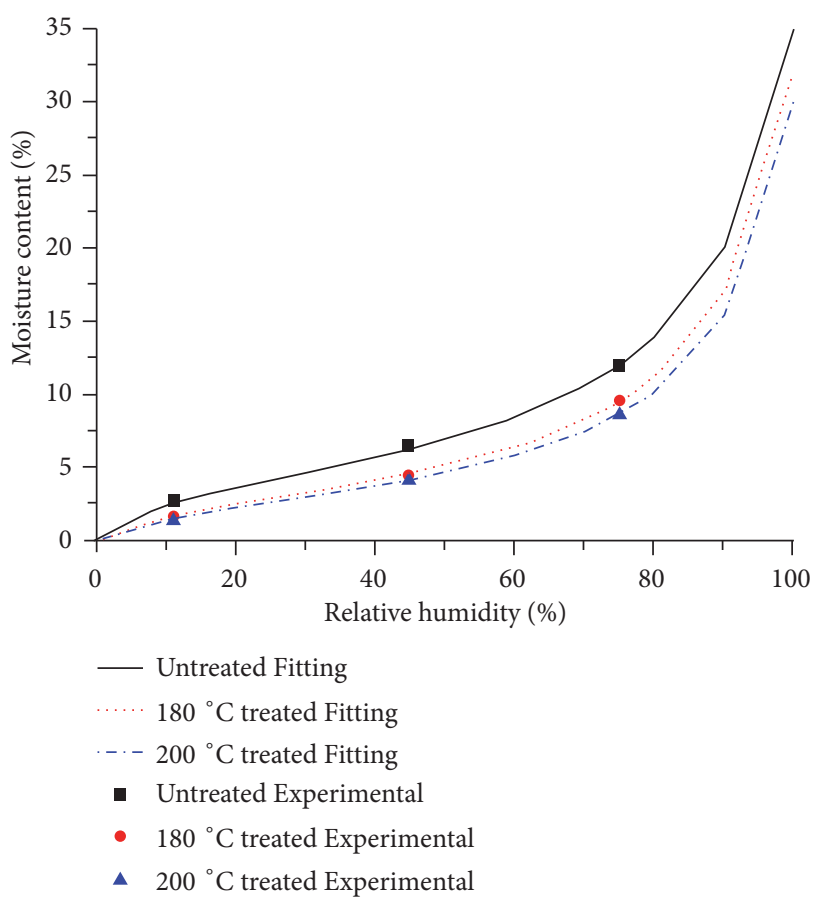

FIGURE 2: Sorption isotherms calculated by $\mathrm{H}-\mathrm{H}$ sorption theory and a comparison with experimental data.

Figure 3 shows the MC of samples for hydrated water and dissolved water. Both of the contents of hydrated water and dissolved water were characterized by a trend in which the untreated sample showed the highest MC, followed by the heat-treated sample at $180^{\circ} \mathrm{C}$ and the heat-treated sample at $200^{\circ} \mathrm{C}$. Furthermore, after heat treatment, the contents of hydrated water of bamboo had been substantially reduced (Figure 3(a)).

The moisture adsorption coefficient $Z$ is the variation of wood MC per unit of RH, which is usually used as an index to evaluate wood hygroscopicity. The coefficients for the samples within the $\mathrm{RH}$ range of $45 \%$ to $75 \%\left(z=\left(M C_{75 \% R H^{-}}\right.\right.$ $\left.M C_{45 \% R H}\right) / 30 \%$ ) are listed in Table 2. It can be found that $Z$ of the untreated sample was 0.19 , close to the values for 28 wood species (0.20) [23]. The lower $Z$ values for the heat-treated samples demonstrated a drop in hygroscopicity.

3.3. Dynamic Sorption at Sinusoidal RH. Figure 4 shows the general $\mathrm{MC}$ responses of heat-treated samples and untreated samples to the sinusoidal RH for 4 cycles. It can be clearly seen that the MCs of all the samples change sinusoidally with the sinusoidal variation of $\mathrm{RH}$, but they lag behind the change of $\mathrm{RH}$ in phase. 


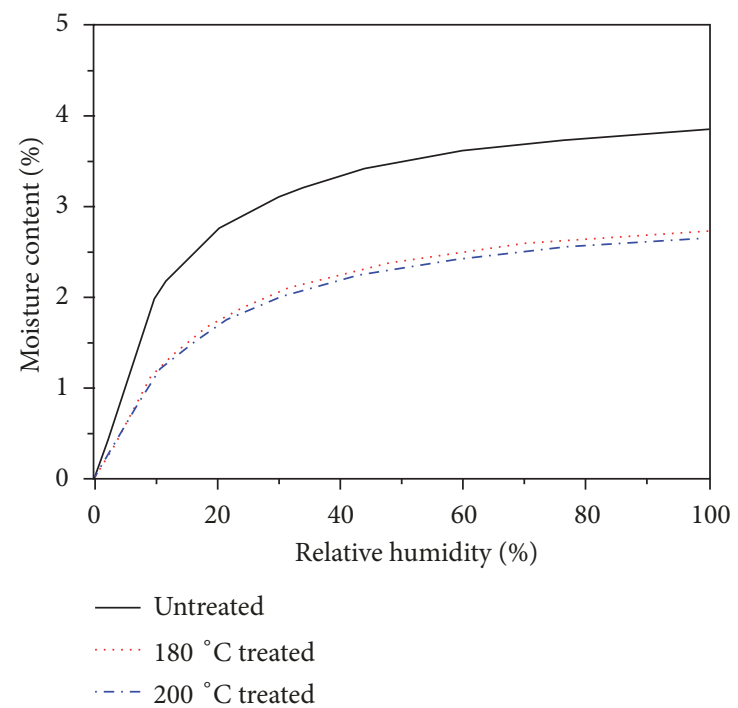

(a)

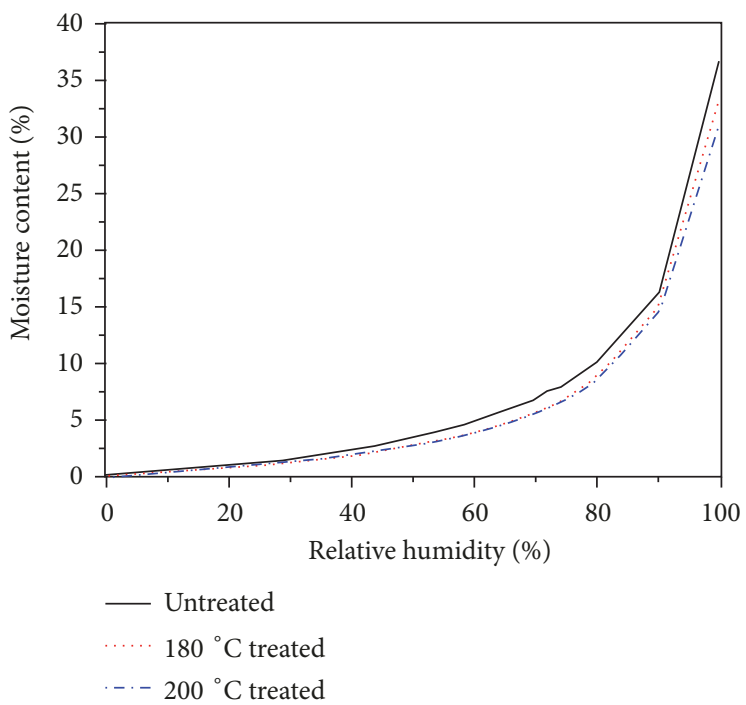

(b)

FIGURE 3: Moisture content of samples for (a) hydrated water and (b) dissolved water.

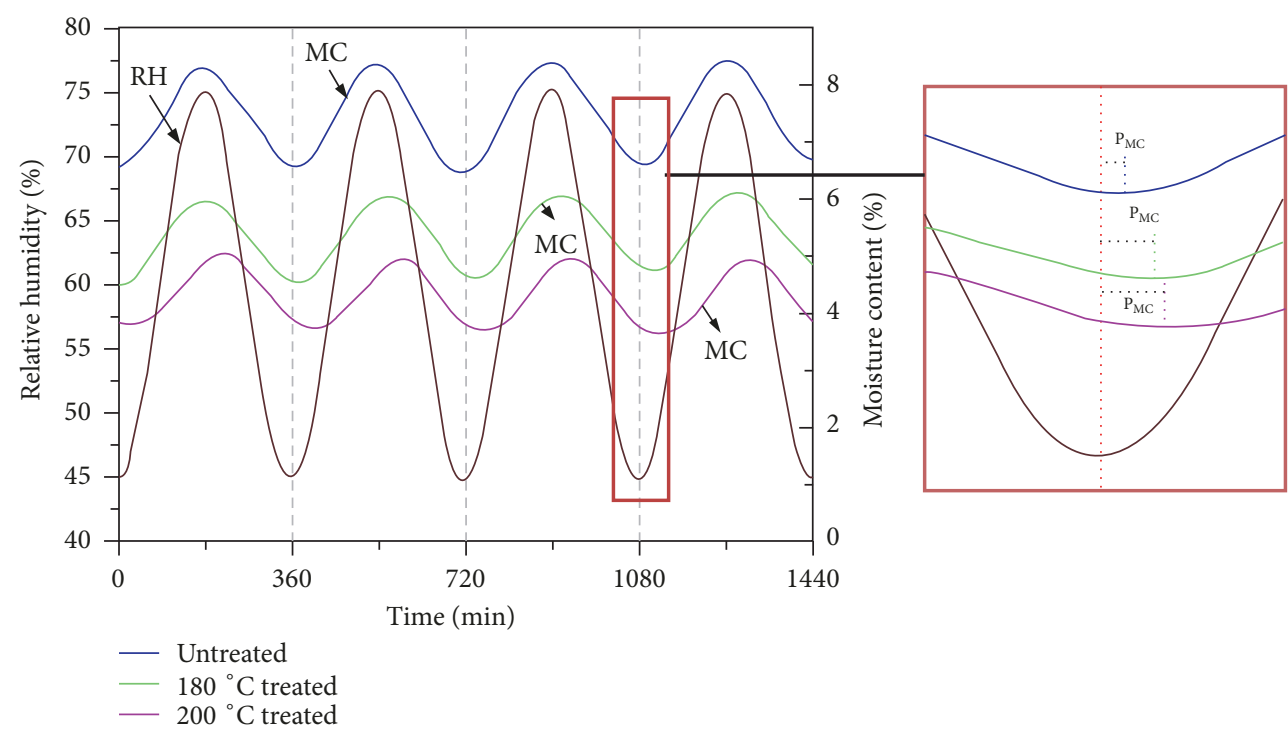

FIGURE 4: Plots of moisture content changes where relative humidity changes sinusoidally at a constant temperature against cyclic time for untreated and heat-treated bamboo samples. $\mathrm{P}_{\mathrm{MC}}$ : phase lag of $\mathrm{MC}$ change.

As seen from Figure 4, the starting points of MC of the three types of samples were different, which was consistent with the static moisture adsorption. This was because they have reached their respective EMC at $45 \% \mathrm{RH}$ after a long period moisture adjustment before the dynamic moisture sorption began. Table 3 lists the amplitude of MC response of all the samples under dynamic conditions and MC increment from $\mathrm{RH} 45 \%$ to $75 \%$. The untreated samples showed the greatest amplitude while the heat-treated samples at $200^{\circ} \mathrm{C}$ showed the smallest. This was because the decrease of hemicellulose reduced the moisture absorption sites. Compared with the results of static moisture absorption, when the RH was changed from $45 \%$ to $75 \%$, the increment of MC for all the samples under dynamic condition was smaller than that under static condition (Table 3). As the $\mathrm{RH}$ was changed sinusoidally, bamboo no longer had enough time to reach the EMC at the specified humidity.

The phase lag of MC reflected the speed of response to $\mathrm{RH}$ change. The larger the phase lag was, the lower the response to the RH change was. As seen from Figure 4, the heat-treated bamboo showed a larger phase lag than untreated bamboo, demonstrating the lower mass transfer rate of moisture after heat treatment.

Figure 5 presents the MC data for heat-treated samples at $200^{\circ} \mathrm{C}$ between the $3 \mathrm{rd}$ wave trough point and the 4 th wave trough point in Figure 4 with sinusoidal RH. An 
TABLE 3: Amplitude of MC response and hysteresis ratio of all the samples under dynamic conditions and $\mathrm{MC}$ increment from RH $45 \%$ to $75 \%$.

\begin{tabular}{lccc}
\hline Sample & \multicolumn{2}{c}{$\begin{array}{c}\text { Dynamic sorption } \\
\text { Amplitude of MC (\%) }\end{array}$} & $\begin{array}{c}\text { Static adsorption (45\%-75\%) } \\
\text { Increment of MC (\%) }\end{array}$ \\
\hline Untreated & 1.86 & 0.828 & 5.44 \\
$180^{\circ} \mathrm{C}$ treated & 1.48 & 0.845 & 5.05 \\
$200^{\circ} \mathrm{C}$ treated & 1.31 & 0.854 & 4.50 \\
\hline
\end{tabular}

${ }^{a}$ Average value with relative humidity (RH) changed sinusoidally between $45 \%$ and $75 \%$.

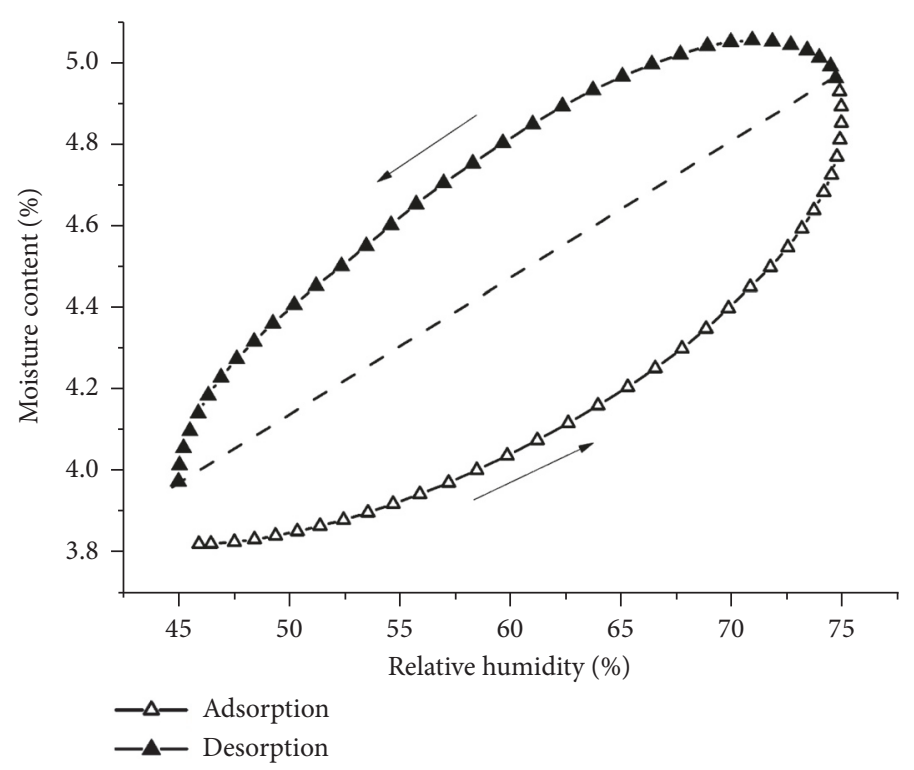

Figure 5: Plots of dynamic moisture content changes against sinusoidal relative humidity for $200^{\circ} \mathrm{C}$ treated bamboo.

obvious sorption hysteresis could be observed. The minimum hysteresis ratio "Ads. MC/Des. MC" for all the samples was calculated (Table 3). After heat treatment, the hysteresis ratio decreased and it was inversely related to the temperature of heat treatment, which could be explained by the relaxation theory. The sorption hysteresis is primarily influenced by the softening of hemicellulose. Therefore, a decrement in sorption hysteresis would follow after the partial removal of hemicellulose.

\section{Conclusion}

In this study, the influence of heat treatment on the adsorption behavior of bamboo at constant relative humidity and its dynamic sorption behavior at sinusoidal relative humidity has been investigated. The hemicellulose of bamboo was greatly removed after the heat treatment. Under the constant condition, the untreated bamboo exhibited the highest moisture content and moisture sorption coefficient, followed by the $180^{\circ} \mathrm{C}$ heat-treated sample and $200^{\circ} \mathrm{C}$ heat-treated sample. Under the dynamic condition, the moisture content of all the sample changed sinusoidally but lagged behind the triggering sinusoidal relative humidity changes. The heattreated samples showed a decrement in the amplitudes of moisture content and an increment in the phase lag. The removal of hemicellulose after heat treatment also led to the reduction in sorption hysteresis of bamboo.

\section{Data Availability}

The data used to support the findings of this study are available from the corresponding author upon request.

\section{Conflicts of Interest}

The authors declare that they have no conflicts of interest.

\section{Acknowledgments}

This work was financially supported by the National Natural Science Foundation of China (Nos. 31870550, 31470591).

\section{References}

[1] T. Li, D.-L. Cheng, M. E. P. Wålinder, and D.-G. Zhou, "Wettability of oil heat-treated bamboo and bonding strength of laminated bamboo board," Industrial Crops and Products, vol. 69, pp. 15-20, 2015.

[2] A. Azadeh and K. Ghavami, "The influence of heat on shrinkage and water absorption of Dendrocalamus giganteus bamboo 
as a functionally graded material," Construction and Building Materials, vol. 186, pp. 145-154, 2018.

[3] R. D. Manalo and M. N. Acda, "Effects of hot oil treatment on physical and mechanical properties of three species of Philippine Bamboo," Journal of Tropical Forest Science, vol. 21, no. 1, pp. 19-24, 2009.

[4] J. Q. Qi, J. L. Xie, X. Y. Huang, W. J. Yu, and S. M. Chen, "Influence of characteristic inhomogeneity of bamboo culm on mechanical properties of bamboo plywood: effect of culm height," Journal of Wood Science, vol. 60, no. 6, pp. 396-402, 2014.

[5] B. Sharma, A. Gatóo, and M. H. Ramage, "Effect of processing methods on the mechanical properties of engineered bamboo," Construction and Building Materials, vol. 83, pp. 95-101, 2015.

[6] C.-H. Lee, M.-J. Chung, C.-H. Lin, and T.-H. Yang, "Effects of layered structure on the physical and mechanical properties of laminated moso bamboo (Phyllosachys edulis) flooring," Construction and Building Materials, vol. 28, no. 1, pp. 31-35, 2012.

[7] A. C. D. Almeida, V. A. D. Araujo, E. A. M. Morales, M. Gava, R. A. Munis, and J. N. Garcia, "Wood-bamboo particleboard: mechanical properties," Bioresources, vol. 12, pp. 7784-7792, 2017.

[8] T. C. Yang, T. L. Wu, K. C. Hung, Y. L. Chen, and J. H. Wu, "Mechanical properties and extended creep behavior of bamboo fiber reinforced recycled poly(lactic acid) composites using the time-temperature superposition principle," Construction \& Building Materials, vol. 93, pp. 558-563, 2015.

[9] Y. M. Zhang, Y. L. Yu, and W. J. Yu, "Effect of thermal treatment on the physical and mechanical properties of phyllostachys pubescen bamboo," European Journal of Wood and Wood Products, vol. 71, no. 1, pp. 61-67, 2013.

[10] B. M. Esteves and H. M. Pereira, "Wood modification by heat treatment: A review," Bioresources, vol. 4, no. 1, pp. 370-404, 2009.

[11] J. H. Kwon, R.-H. Shin, N. Ayrilmis, and T. H. Han, "Properties of solid wood and laminated wood lumber manufactured by cold pressing and heat treatment," Materials and Corrosion, vol. 62, pp. 375-381, 2014.

[12] M. Bak and R. Németh, "Changes in swelling properties and moisture uptake rate of oil-heat-treated poplar (Populus $\times$ euramericana cv. pannónia) wood," Bioresources, vol. 7, no. 4, pp. 5128-5137, 2012.

[13] D. S. Korkut and B. Guller, "The effects of heat treatment on physical properties and surface roughness of red-bud maple (Acer trautvetteri Medw.) wood," Bioresource Technology, vol. 99, no. 8, pp. 2846-2851, 2008.

[14] G. Gündüz, S. Korkut, and D. S. Korkut, "The effect of heat treatment on physical and technological properties and surface roughness of Camiyani Black Pine (Pinus nigra Arn. Subsp. Pallasiana var. pallasiana) wood," Bioresource Technology, vol. 99, no. 7, pp. 2275-2280, 2008.

[15] C.-H. Lee, T.-H. Yang, Y.-W. Cheng, and C.-J. Lee, "Effects of thermal modification on the surface and chemical properties of moso bamboo," Construction and Building Materials, vol. 178, pp. 59-71, 2018.

[16] T.-H. Yang, C.-H. Lee, C.-J. Lee, and Y.-W. Cheng, "Effects of different thermal modification media on physical and mechanical properties of moso bamboo," Construction and Building Materials, vol. 119, pp. 251-259, 2016.

[17] R. Wahab, A. Mohamad, H. W. Samsi, and O. Sulaiman, "Effect of heat treatment using palm oil on properties and durability of
Semantan bamboo," Journal of Bamboo and Rattan, vol. 4, no. 3 , pp. 211-220, 2005.

[18] A. P. Schniewind, "Creep-rupture life of Douglas-fir under cyclic environmental conditions," Wood and Science Technology, vol. 1, no. 4, pp. 278-288, 1967.

[19] R. J. Zhao, Z. H. Jiang, C. Y. Hse, and T. F. Shupe, "Effects of steam treatment on bending properties and chemical composition of moso bamboo (Phyllostachys pubescens)," Journal of Tropical Forest Science, vol. 22, no. 2, pp. 197-201, 2010.

[20] A. J. Hailwood and S. Horrobin, "Absorption of water by polymers: Analysis in terms of a simple model," Transactions of the Faraday Society, vol. 42, pp. B084-B092, 1946.

[21] T. Yang, E. Ma, and J. Zhang, "Dynamic moisture sorption and hygroexpansion of Populus euramericana Cv. under two cyclic hygrothermal conditions," Holzforschung, vol. 70, no. 12, pp. 1191-1199, 2016.

[22] H. Zhou, R. Xu, and E. Ma, "Effects of removal of chemical components on moisutre adsorption by wood," Bioresources, vol. 11, no. 2, pp. 3110-3122, 2016.

[23] D. Noack, E. Schwab, and A. Bartz, "Characteristics for a judgment of the sorption and swelling behavior of wood," Wood and Science Technology, vol. 7, no. 3, pp. 218-236, 1973. 


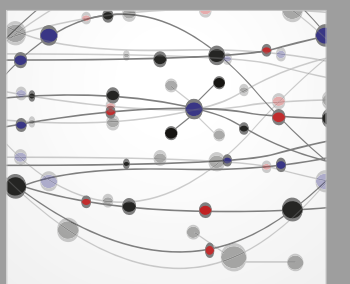

The Scientific World Journal
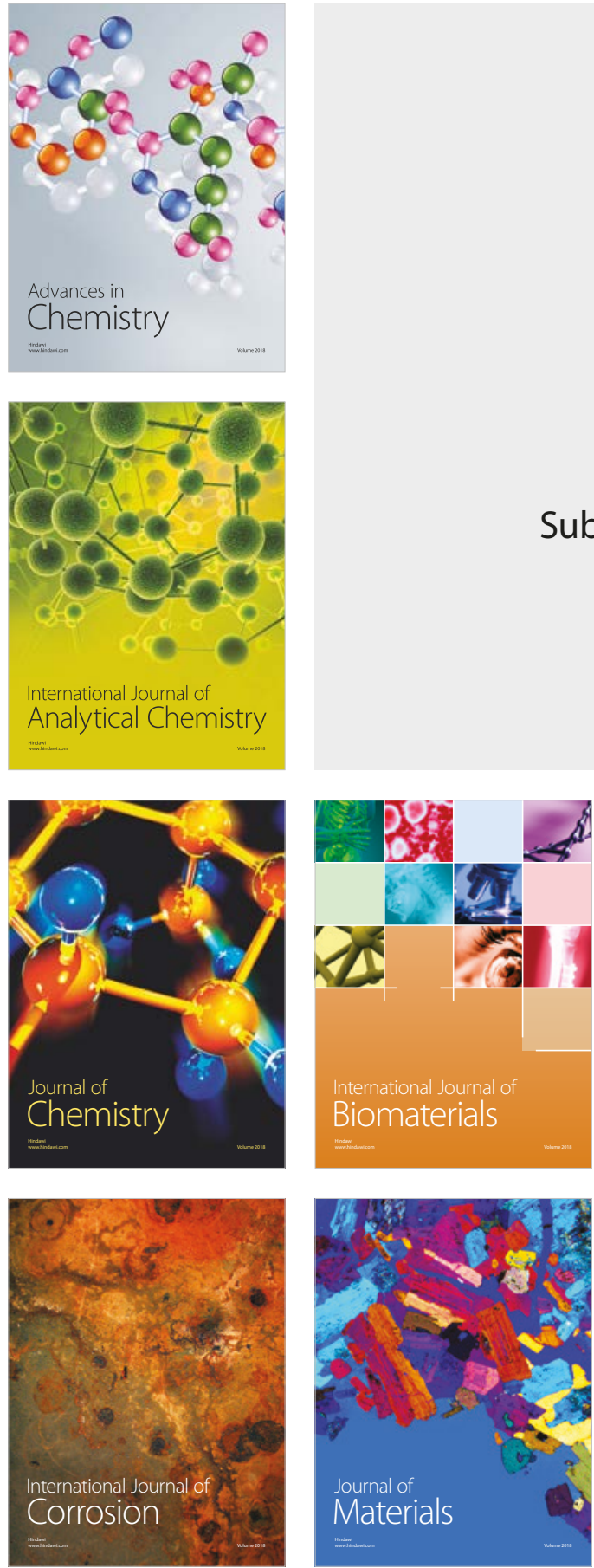

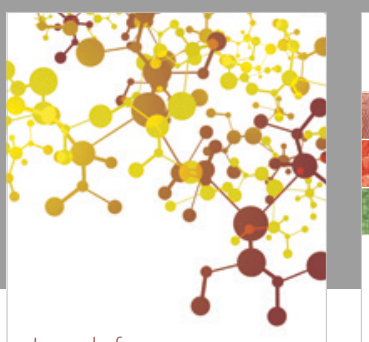

Journal of

Applied Chemistry
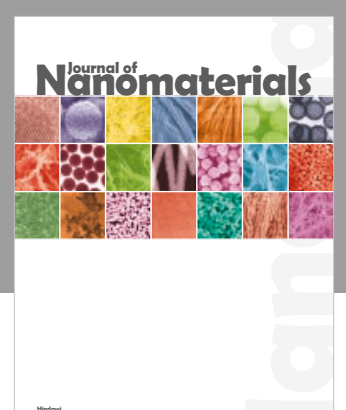

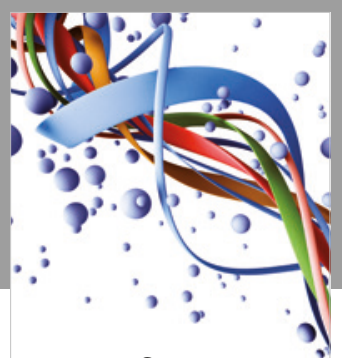

Scientifica

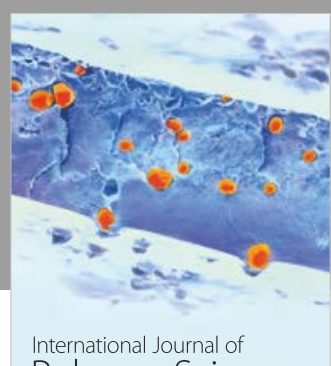

Polymer Science

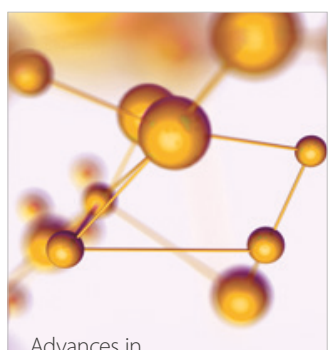

Physical Chemistry
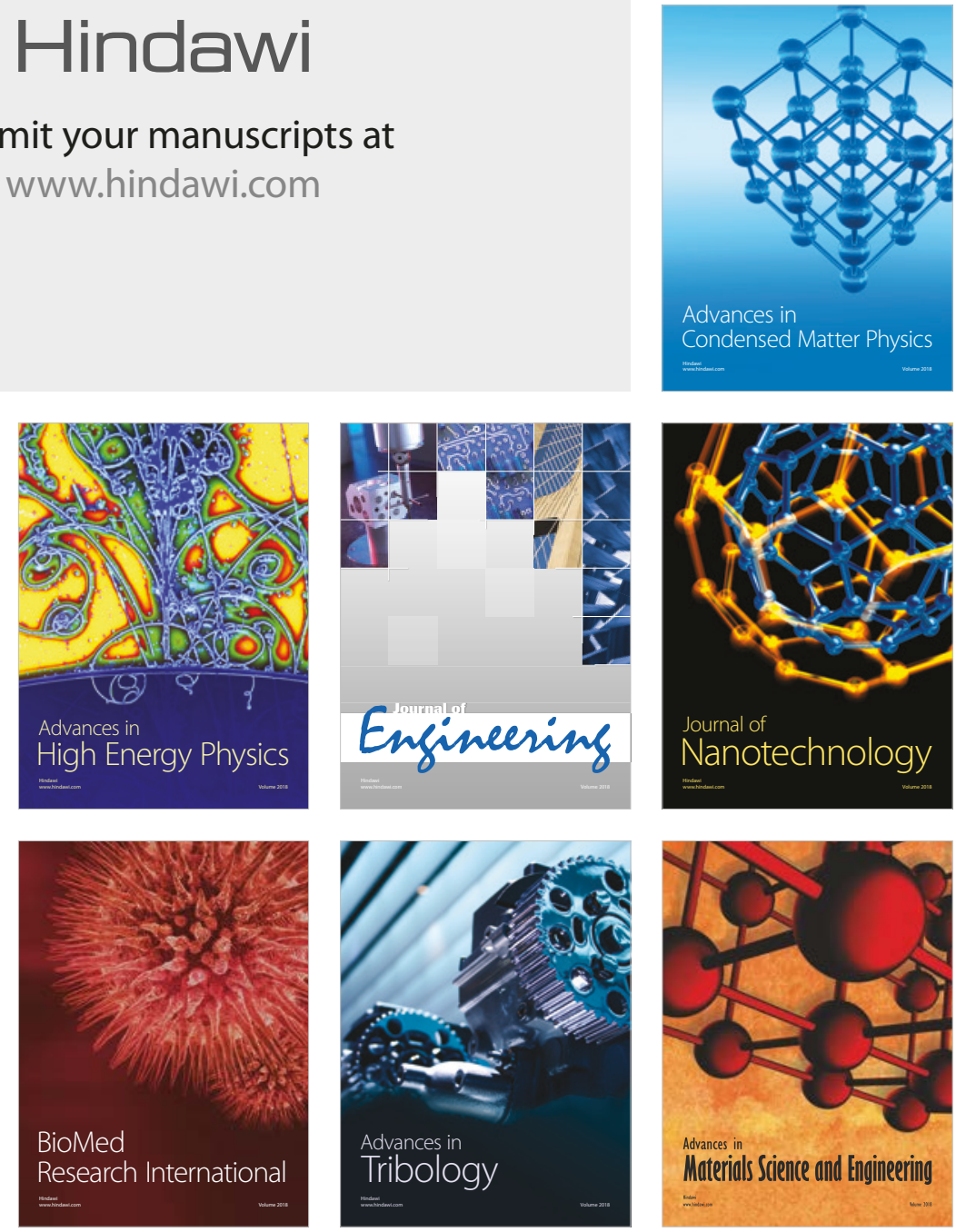